\title{
Examining Motivations of Volunteer Drivers in a Senior Ride Program
}

\author{
Debra Gibbs*, Logan Garman, Courtney Janusz, Tiffany Lee, Emma Mace, Mackenzie Mellinger, \\ Lauren Schar
}

School of Occupational Therapy, Belmont University, Nashville, Tennessee, USA

Email: *debra.gibbs@belmont.edu

How to cite this paper: Gibbs, D., Garman, L., Janusz, C., Lee, T., Mace, E., Mellinger, M. and Schar, L. (2019) Examining Motivations of Volunteer Drivers in a Senior Ride Program. Open Access Library Journal, 6: e5630.

https://doi.org/10.4236/oalib.1105630

Received: July 23, 2019

Accepted: August 24, 2019

Published: August 27, 2019

Copyright $\odot 2019$ by author(s) and Open Access Library Inc.

This work is licensed under the Creative Commons Attribution International License (CC BY 4.0).

http://creativecommons.org/licenses/by/4.0/

\section{(c) (i) Open Access}

\begin{abstract}
Objective: This paper explores the motivations of volunteer drivers for a senior ride program. The results were used to identify suggestions for the recruitment and retention of volunteers. Method: An online survey, consisting of a demographics form and the Volunteer Functions Inventory (VFI), was completed by 33 participants recruited from Senior Ride Nashville. The survey results were analyzed and used to develop questions for a focus group. Two focus groups, for a total of 9 participants, were conducted to further explore volunteer motivations, verify VFI findings and identify themes relating to volunteer motivations. Results: Statistically significant differences were identified among the VFI scores with the highest median values being Values followed by Understanding and Enhancement. Scores on the VFI Values scale were statistically and significantly different by marital status and likelihood to volunteer in the future. Scores on the VFI Understanding, Enhancement and Protective scores expressed significance among those likely to volunteer in the future. There was a statistically significant inverse correlation of age with the VFI Career motivation score. Focus group revealed three themes of motivations to volunteer including the following: altruism, personal values, and connectedness. Conclusion: This research study found that volunteers for Senior Ride Nashville are most often motivated by an altruistic desire to serve others. Volunteer ride programs promote access to transportation and community participation for older adults, enhancing their occupational engagement. Recruitment and retention efforts should focus on the relational aspect of the volunteer experience.
\end{abstract}

\section{Subject Areas}

Sociology 


\section{Keywords}

Volunteering, Transportation, Motivation, Older Adults, Quality of Life

\section{Introduction}

Driving and accessing transportation are considered instrumental activities of daily living (IADLs), vital to independent living in one's community or aging in place [1]. In Middle Tennessee alone, between the years 2015 and 2030, the number of individuals over the age of 65 is projected to increase drastically by $32 \%$ [2]. The U.S. Census Bureau estimated 35.5\% of community dwelling adults over 65 have some type of disability [3]. Physical and cognitive limitations can prevent older adults from driving or accessing traditional transportation options within their communities even though they are still capable of remaining in their homes. Occupational therapy advocates for the rights of individuals to have equal access to services promoting full participation in community living, including transportation and adequate mobility options [4] [5] [6]. Life expectancy has increased in recent years and humans are now outliving their driving expectancies. While men are likely to live as many as six years past the time period where they can safely drive, women can live as many as 10 years [7]. In addition to outliving the safe driving expectancy, $85 \%$ of Nashville seniors in the $65-79$ age range have poor access to transit, implying there is a definite need for alternative transportation options for older adults [8]. Volunteer ride programs are necessary to support the quality of life for aging adults [5].

Volunteer ride programs are being organized across the country by community-based organizations offering a wider range of services to meet older adults' varying transportation and community needs [7]. Senior Ride Nashville, a middle Tennessee senior ride program, provides door-through-door service and low-cost rides to qualifying seniors through the use of volunteer drivers. Presently, only $24.9 \%$ of residents in the Greater Nashville area volunteer for some agency or service [9]. Programs like Senior Ride Nashville support active engagement in the community and contribute to health, wellness, and quality of life for all individuals [5]. The recruitment and retention of volunteers are paramount to the success of the Senior Ride Nashville program, as well as many other volunteer led programs. The purpose of this study is to examine the motivations of volunteer drivers for Senior Ride Nashville using the Volunteer Functions Inventory (VFI) [10] and to identify strategies for Senior Ride Nashville to support individuals in their volunteer role.

Volunteerism is defined as "long-term, planned, prosocial behaviors that benefit strangers, and usually occur in an organizational setting" [11]. A volunteer driver is "an individual who volunteers themselves and their automobiles to take seniors (and sometimes people with limited disabilities) to life sustaining and life-enriching activities" [7]. Clary and Snyder [12] argued that volunteering has 
several key characteristics including the following: seeking out opportunities to help, choosing particular organizations in which to help, committing time and energy, and making a lasting decision to pursue volunteering. Hustinx, Cnaan, and Handy [13] completed a content analysis of the definition of volunteering and found that all definitions of volunteering consider the provision of time, labor and expertise.

There are many theories that explore the nature of why individuals begin to volunteer and continue to volunteer. Thoits and Hewitt [14] identified five models of volunteering that acknowledge various factors that motivate volunteers. The volunteer motivations model describes different functions that volunteering can serve in a person's life. Motivations can include learning new skills, increasing self-confidence, and enhancing career development. There may be one motivator or multiple motivators incentivizing volunteers. For example, Morrow-Howell, Lee, McCrary and McBride [15] discovered younger populations' motivations are more often aligned with the volunteer motivations model, citing career development and building social relationships as important motivators.

Some volunteers contribute their beliefs and values as primary motives for volunteering. These volunteers report a strong conviction for civic responsibility and would be associated with the values and attitudes model [14]. In this model, altruism and humanitarian values are frequent motivating factors, especially among older adults [15]. Previous volunteer experiences can develop an individual's sense of identity. The role-identity model characterizes volunteers who continuously serve since volunteering has become part of their identity. Similarly, a person is likely to volunteer more with groups or communities with whom they identify, such as a veteran helping a military organization. An established identity as a volunteer is a strong predictor of continued volunteerism [14].

In the volunteer personality model, helpfulness and empathy are key traits exhibited by volunteers [14]. A prosocial personality is linked with longer volunteerism history and participation in various volunteer activities. Finkelstein [16] found that higher intrinsic motivations (i.e. helpfulness and empathy) were evidence of having a prosocial attitude and help establish volunteer role identity. Additionally, a person who is highly motivated, self-confident, and emotionally stable may be better prepared to volunteer.

In the personal well-being model, Thoits and Hewitt [14] "examine personality characteristics and physical and mental health as resources necessary for seeking out (or being sought for) and becoming involved in community service" (p. 117). The authors suggest if someone feels in control of their life, is confident in their abilities to pursue their dreams and has a healthy value of their own self-worth, they are usually in good physical and mental health. When individuals have access to personal resources it is easier for them to pursue their goals. Thus, someone who is considered to have an overall higher well-being is more likely to volunteer [14].

Widjaja [17] identifies unidimensional, two-dimensional, three-dimensional, 
and multidimensional models of volunteers, finding that multidimensional models are the most widely used. Hustinx et al. [13] identify volunteerism from four different viewpoints, which each take on their own theory of why people volunteer. Economists view volunteering as a paradox where helping others is ultimately for self-gain and fulfillment. On the other hand, sociologists view volunteering as a way to express altruism, compassion, and increase socialization [13]. Finkelstein [16] combines motivational theories with role identity theory to explain who volunteers are and why they volunteer. The common consensus among researchers of volunteerism is that there is not an integrated theory, but volunteering occurs in a multidimensional model that encompasses several theories [13] [16] [17].

Clary et al. [10] proposed a multidimensional model offering six categories of volunteer motives, leading to the development of the Volunteer Functions Inventory (VFI) survey. The VFI reflects the functional motivation theory, which states that people volunteer to fulfill certain goals and psychological functions. Individuals can perform the same type of volunteer work to obtain different goals or fulfill different psychological functions [17]. According to the six motives developed by Clary et al. [10] volunteers are characterized by their individual psychological needs and personality traits [13].

Previous studies on volunteering across the lifespan have indicated there are specific characteristics associated with volunteers. Pardasani [18] reported that "women, adults with post-graduate education, participants older than 69, and those with an annual income of over $\$ 50,000$ were more likely to report an interest in volunteering" (p. 322). The largest survey conducted of 714 volunteer drivers across the country concluded the majority (63\%) of respondents were age 65 or older [7]. Delicado et al. as cited in Agostinho \& Paco, [19] determined people who are at the top of their working life with the highest professional and family obligations are among the highest to regularly volunteer. The same study also discovered $64 \%$ of volunteers are married, half of which have children of their own, and $65 \%$ of volunteers have a high school degree or higher education, therefore, expressing a diversity in people who choose to volunteer.

McNamara and Gonzales [20] suggested that age is not a determining factor for volunteerism, but individual resources determine an individual's inclination to volunteer, specifically for individuals over 50 years of age. The study concluded that human capital (education, income, and functional health) is positively associated with participation in volunteer activities. Social capital is positively associated with altruistic and protective motivations to volunteer [21]. In relation to social capital, the quantity and quality of social linkages are impacted by family, paid work, and community [20]. Lastly, religious activity is positively associated with participating in volunteer activities [20].

Many studies examine the motivations of volunteers in a variety of settings; however, studies focusing specifically on the motivations of volunteer drivers are limited. In one particular survey of volunteer drivers, the qualitative motivations included the following: meeting new people, having interesting experiences, 
contributing time rather than money, and giving back to the community [7]. In the same survey, volunteer drivers reported socialization and "getting to know riders" among the top reasons for being a satisfied volunteer. In addition, the volunteers reported the greatest challenges of being a volunteer driver as providing physical assistance, passenger aggressiveness, and not acquiring enough personal information about the rider. Kerschner et al. suggested "transportation services that involve volunteer drivers benefit from understanding what motivates people to become volunteer drivers and what satisfies them and ensure that avenues are available for meeting volunteer expectations and creating satisfying volunteer experiences" ( p. 394) [7].

An individual's decision to volunteer depends on expectations, motivations, values, and level of satisfaction [7]. The Volunteer Functions Inventory (VFI) is a reliable measure used to determine volunteer motivations. It has two practical implications for organizations which include aiding in the recruitment of volunteers and decreasing the turnover rate of volunteers [17]. Stukas, Hoye, Nicholson, Brown, and Aisbett [22] used the VFI to survey 4085 Australians, aged 18 89 years, regarding their motivations for volunteering. The results revealed values are the most important motive, while careers are the least important motive for volunteering. The study found people who volunteered for "other-oriented" reasons, corresponding to the values and social function of the VFI, were more likely to report higher levels of well-being, satisfaction, and higher intention to continue volunteering [22].

In a study by Principi, Schippers, Naegele, Di Rosa, and Lamura [21] the VFI was used to measure the volunteer motivations of older adults according to their human, social, and cultural capital. The values function was found to be associated with human, social, and cultural capital. The understanding function (increasing knowledge) was not associated with any form of capital, which could indicate that gaining knowledge is not as important to older volunteers [21]. Allison, Okun, and Dutridge [23] used the VFI in conjunction with open-ended questions to find additional motivations of volunteers. The participants rated the values motive as most important, while career and social motives were rated as least important, which corresponds to the findings from the study by Stukas et al. [22] mentioned above.

The motives of a volunteer are complex and include many dimensions therefore, it is difficult to discern or isolate one primary reason for volunteerism. A single theory cannot sufficiently explore or explain the scope of motivations that drive individuals to give their time and resources to benefit another person, group, or organization [13]. The life-cycle of a volunteer can change frequently, and it is helpful to identify the most relevant reasons a person would volunteer throughout stages in their lives.

\section{Method}

\subsection{Research Design}

The research design was a mixed-method, sequential exploratory design. This 
study collected and analyzed quantitative data through an online survey, followed by a verification process of the VFI motivations using a ranking of the 6 volunteer functions, and concluded with an analysis of qualitative information via focus group [24]. A pragmatic worldview best fits this study design because it draws from both qualitative and quantitative data providing individual researchers freedom to choose the methods, techniques, and procedures that best meet the needs of the study [25].

A comprehensive literature review was completed to determine the extent of research on the motivations of volunteers, volunteer drivers, and the effects of driving cessation on older adults. A Qualtrics $\odot$ survey was created consisting of a demographics survey (Appendix A) and the VFI [10]. An expert panel reviewed the demographics survey to ensure relevance and appropriateness of the questions for the intended population. The VFI [10] was selected as a valid and reliable measure to further analyze the motivators of volunteering and permission to use was granted by the author. The Belmont University Institutional Review Board provided approval and participant consent was obtained at all stages of the research process.

Participants were recruited from a local organization, Senior Ride Nashville. In the first phase of the research, the Qualtrics $\odot$ survey was sent to participants via an email from Senior Ride Nashville. In the second phase, Senior Ride Nashville invited volunteers to a focus group via email. The focus group participants completed a ranking of the six functions of the VFI prior to the focus discussion to verify the findings from the survey. The two focus groups were audio recorded and note takers were utilized to ensure accurate documentation of each participant's responses. For confidentiality, the names were removed from the notes and were referenced as Participant 1, Participant 2, and so on. To analyze the focus group data a triangulation process was utilized to verify the findings and create themes.

\subsection{Participants}

Senior Ride Nashville sent an email to all of their current active volunteer drivers $(\mathrm{n}=74)$ explaining the purpose of the study and a link to the online Qualtrics $\odot$ survey. Upon clicking on the survey link, participants read and gave consent to participate in the study. Participants were excluded only if they did not speak English. A reminder email was sent two weeks following the initial invitation. The survey remained open for one month and was completed by 33 participants (45\% response rate).

Participants for the focus group were recruited in the same manner as the online survey. An email was sent to the current volunteer drivers of Senior Ride Nashville with an explanation of and invitation to the focus group. A reminder email was sent to participants one week after the initial invitation. Thirteen volunteer drivers responded to the invitation, with nine participants attending the focus group at the Senior Ride Nashville office. The nine participants were divided into two focus groups consisting of a facilitator and at least one note taker. 


\section{Measures}

\subsection{Volunteer Functions Inventory}

The Volunteer Functions Inventory (VFI) developed by Clary et al. (1998) is a functional multi-factoral instrument to examine volunteers' motivations. The VFI consists of 30 statements on volunteering in which respondents indicate the importance of each one on a seven-point Likert scale, ranging from one, not at all important, to seven, extremely important. It characterizes six general psychological functions that motivate individuals to volunteer. The six functions included in the VFI are values, understanding, social, career, protective, and enhancement motives. Examples of questions include the following: I feel it is important to help others (values), volunteering lets me learn through direct, hands-on experience (understanding), volunteering makes me feel better about myself (enhancement), volunteering can help me get my foot in the door at a place where I would like to work (career), people I know share an interest in community service (social), and volunteering is a good escape from my own troubles (protective) [12]. The VFI is a reliable and valid tool to measure the motivations underlying volunteerism [10]. The reliability of the motivational function scales in this study had adequate Cronbach Alpha values as follows: Protective-0.73, Values-0.86, Career-0.88, Social-0.69, Understanding-0.66, and Enhancement- 0.81 . The VFI provides a thorough analysis of the many intrinsic and extrinsic motivators of volunteerism [16].

\subsection{Focus Group Questions}

Focus group questions (Appendix B) were developed after analyzing the responses on the VFI survey and consulting the literature. Senior Ride Nashville staff reviewed the questions and requested additional focus group questions to address training and recruitment of new volunteers. The researchers edited the questions based on feedback from Senior Ride Nashville staff.

\section{Data Analysis and Results}

\subsection{Quantitative Data Analysis}

The quantitative data were analyzed using IBM SPSS Statistics 25 . Graphical and descriptive statistical summaries ( $\mathrm{min}, \mathrm{max}$, median, interquartile range) were used to determine which of the motivating factors were rated most highly by the volunteers. A Friedman Test was used to determine the statistical significance ( $\mathrm{p}$ $<0.001$ ) of the differences in scores among the VFI functions. Subsequently, Kruskal-Wallis Tests and Spearman rank correlations were used to explore if any demographic characteristics were associated with the VFI scores. If a statistically significant difference was found among 3 or more demographic groups using the Kruskal-Wallis, pairwise post-hoc comparisons were conducted using Tukey Tests and Mann-Whitney U-Tests of the ranked values to determine specifically where the differences existed. An alpha of $0.05(\mathrm{p}<0.05)$ was used for determining statistical significance. 


\subsection{Quantitative Data Results}

Thirty-four people responded to the survey sent to all current Senior Ride Nashville volunteers. Of the 34 volunteers who responded, 33 surveys were completed sufficiently to be included in the analysis (refer to Table 1 for summary of demographic characteristics). A more detailed analysis of the demographic information provided a volunteer profile for Senior Ride Nashville. Sixty three percent of the volunteers are over 65 years of age, $70 \%$ are females with $39 \%$ of those being single, widowed or divorced. Eighty five percent of the volunteers described their health as good or very good, 59\% described themselves as very religious and $52 \%$ reported a high financial security.

The distributions of the VFI motivational scales are illustrated in Figure 1 and summarized in Table 2. There was a statistically significant difference among these VFI scores (Friedman test: $X^{2}(5)=133.62, \mathrm{p}<0.001$ ). The VFI motivating functions, ranked from greatest to least by median value are as follows: Values = 32.00 , Understanding $=24.00$, Enhancement $=22.00$, Social $=16.00$, Protective $=$ 14.00 , and Career $=5.00$. In the ranking verification prior to the focus group, Values was also identified by $100 \%$ of focus group participants as the number one motivating factor.

Table 1. Demographic characteristics of volunteer drivers from part I online survey.

\begin{tabular}{|c|c|c|c|}
\hline Characteristic & $\begin{array}{l}\text { Volunteer Driver } \\
\qquad(\mathrm{N}=33)\end{array}$ & Characteristics & $\begin{array}{l}\text { Volunteer Driver } \\
\qquad(\mathrm{N}=33)\end{array}$ \\
\hline Age & \multicolumn{3}{|c|}{ Employment } \\
\hline Age Range & $29-75$ & Part-time & 9 \\
\hline Median Age & 67 & Full-time & 6 \\
\hline 65 and older & 20 & & \\
\hline Gender & & Retired & 17 \\
\hline Male & 10 & Not-emnloved & 1 \\
\hline 65 and older & 6 & Not-empioyed & 1 \\
\hline Female & 23 & \multirow{2}{*}{ Financial Security } & \\
\hline 65 and older & 14 & & \\
\hline Marital Status & & Very Low & 1 \\
\hline Married & 19 & Low & 0 \\
\hline Single & 7 & Medium & 13 \\
\hline Divorced/Separated & 4 & High & 17 \\
\hline Widowed & 3 & Very High & 2 \\
\hline Living Arrangement & & Religious & \\
\hline With family and children & 9 & Not at all & 3 \\
\hline With non-family members & 2 & Somewhat & 7 \\
\hline Alone & 10 & Neutral & 1 \\
\hline With family without children & 12 & A little & 3 \\
\hline Education & & Very & 19 \\
\hline High School Graduate & 2 & & \\
\hline Some College & 6 & & \\
\hline College Graduate & 13 & & \\
\hline Post-Professional Graduate & 12 & & \\
\hline
\end{tabular}




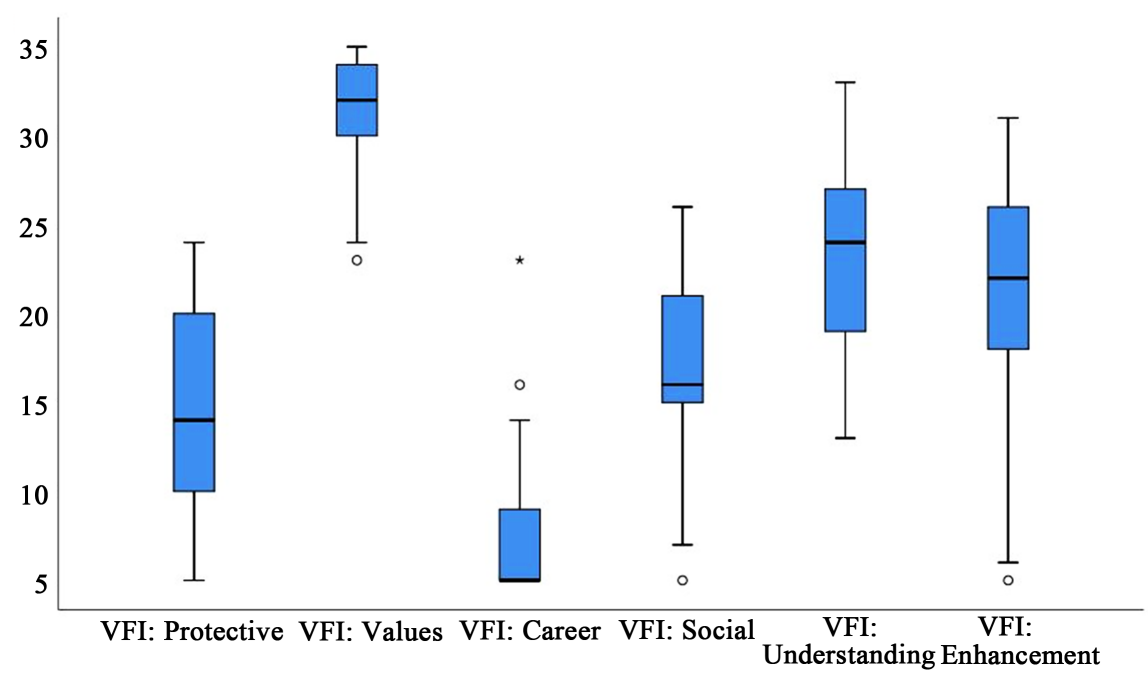

Figure 1. VFI function scores low, high and median.

Table 2. Descriptive summaries of the VFI scores $(\mathrm{N}=33)$.

\begin{tabular}{ccccc}
\hline VFI Scale & Median & IQR & Min & Max \\
\hline Protective & 14 & $9-20$ & 5 & 24 \\
Values & 32 & $29-34$ & 23 & 35 \\
Career & 5 & $5-9$ & 5 & 23 \\
Social & 16 & $14-21$ & 5 & 26 \\
Understanding & 24 & $19-27$ & 13 & 33 \\
Enhancement & 22 & $17-26$ & 5 & 31 \\
\hline
\end{tabular}

Scores on the VFI Values scale were statistically significantly different by marital status (Kruskal-Wallis test: $\left.X^{2}(3)=7.89, \mathrm{p}=0.048\right)$ and by the participant's report of a change in the frequency of rides (Kruskal-Wallis test: $X^{2}(3)=7.68, \mathrm{p}$ $=0.021$ ). Post-hoc tests revealed that those who were widowed (median $=25$, $\min =35, \max =35)$ reported higher Values scores than did those who were married $($ median $=31, \min =27, \max =34)$ or single $($ median $=32, \min =24$, $\max =35)$ (Tukey test, $\mathrm{p}<0.05)$.

Scores on the VFI Values scale were statistically significantly different by marital status (Kruskal-Wallis test: $X^{2}(3)=7.89, \mathrm{p}=0.048$ ) and by the participant's report of a change in the frequency of rides (Kruskal-Wallis test: $X^{2}(3)=7.68, \mathrm{p}$ $=0.021$ ). Post-hoc tests revealed that those who were widowed (median $=25$, $\min =35, \max =35)$ reported higher Values scores than did those who were married $($ median $=31, \min =27, \max =34)$ or single $($ median $=32, \min =24$, $\max =35$ ) (Tukey test, $\mathrm{p}<0.05)$.

None of the demographic characteristics were statistically significantly associated with the VFI Understanding scores. However, there was a statistically significant difference in those scores between the group who stated that they were very likely to volunteer in the future and those who stated they were somewhat or simply likely to volunteer (Mann-Whitney test: $z=2.87, \mathrm{p}=0.004$ ). Those very likely had a higher median score $(25.5, \min =13, \max =33)$ than did those 
in the other group (median $=16, \min =15, \max =23$ ).

As with the Understanding scores, there was also a statistically significant difference in the VFI Enhancement scores between the group who stated that they were very likely to volunteer in the future and those who stated they were somewhat or simply likely to volunteer (Mann-Whitney test: $z=2.49, \mathrm{p}=$ 0.013). Those very likely to volunteer in the future also tended to have a higher Enhancement score (median $=23.5, \min =9, \max =31$ ) than did those stating "somewhat likely" or "likely" (median $=16, \min =5, \max =21$ ).

No statistically significant associations of demographics or volunteer frequency characteristics were observed with the VFI Social scores $(p>0.05)$. Yet, once again there was a statistically significant difference in the VFI Protective scores between the group who stated that they were very likely to volunteer in the future and those who stated they were somewhat or simply likely to volunteer (Mann-Whitney test: $z=3.17, \mathrm{p}=0.002$ ). Similar to the Understanding and Enhancement scores, those participants reporting that they were very likely to volunteer in the future tended to also have a higher Protective scores (median = 16.5 , $\min =5, \max =24)$ than did those stating "somewhat likely" or "likely" ( median $=7, \min =5, \max =10)$.

Finally, there was a statistically significant inverse correlation of age with the VFI Career motivation score $\left(r_{s}=0.0 .51, \mathrm{p}=0.003\right)$. Additionally, those scores differed among the financial security status reported by the participants (Kruskal-Wallis test: $X^{2}(2)=7.82, \mathrm{p}=0.020$ ). Post-hoc tests revealed that those who reported a "Medium" level of financial security tended to have a higher Career score $($ median $=9, \min =5, \max =23$ ) than did those reporting high or very high levels of security (high: median $=5, \min =5, \max =14$; very high: median $=$ $5, \min =5, \max =5)($ Tukey test, $\mathrm{p}<0.05)$.

\subsection{Qualitative Data Analysis}

The researchers followed the six-step process by Braun and Clarke [26] to analyze data from the focus group. Four researchers examined individual copies of audio transcripts and notes to identify any repeated words, phrases, or concepts. Once each researcher completed their individual coding, a group discussion commenced to develop a thematic map as a visual display to organize and synthesize the codes that were identified. Preliminary themes and subthemes emerged. Two additional researchers validated the themes that were discovered. A second meeting was used to review, define, and refine the initial themes. Clear definitions were established for each theme. The research team reexamined the codes to determine if the codes were grouped together appropriately and if the themes were representative of the codes' meaning.

\subsection{Qualitative Data Results}

The results of the qualitative analysis came from two focus groups totaling nine participants. The median age of participants was 67 years and $89 \%$ of participants were female. Three themes identified in the qualitative analysis included 
altruism, personal values, and connectedness. Table 3 provides an overview of comments, grouped by themes, from participants of the focus group.

Altruism is defined as "the principle or practice of unselfish concern for or devotion to the welfare of others" [27]. Altruism can be considered as two parts. First, volunteer drivers identify with the feelings or experiences of the older adult rider. One participant offered, "I feel their isolation ... [it] hurts me." Another participant empathized because they had to take away the keys from their own parents or grandparents stating, “... taking the car keys away from my mother was very traumatic ... and that really weighed on my heart." As a result, these feelings produced empathy or compassion for the riders. The second part of altruism requires an act to take place. Volunteers recognized the needs of the riders especially for transport to and from doctor's appointments or to get groceries. One driver stated, “... they wouldn't get to the doctor's office if I was not there." These needs become a high priority for the volunteer which will then react by volunteering to ensure the needs of riders are met. Volunteers recognized that these individual's quality of life was negatively impacted by not having means for transportation which contributes to their strong desire to serve this population.

Personal values are defined by the Occupational Therapy Practice Framework: Domain \& Process [1] as "principles, standards, or qualities considered worthwhile by the client who holds them" (p. S7). Many volunteers believed that volunteering is something everyone should do, and it is part of what makes a good person. They viewed volunteering as a way to help the community and as part of each person's civic duty in society. They also identified that they may need a similar service one day. One participant stated "I thought the time may come when I may need this service."

Table 3. Thematic respondent sampling.

\begin{tabular}{|c|c|}
\hline Theme & Response \\
\hline Altruism & $\begin{array}{l}\text { - "I mean, they wouldn't get to the doctors office if I was not there." } \\
\text { - "The first thing he said when he got in the car was, 'I'm albino and I'm blind,' so he has a real need." } \\
\text { - "II like to take people to necessary things that if it doesn't get done their quality of life is affected." } \\
\text { - "I think for some reason emotionally, their isolation hurts me." }\end{array}$ \\
\hline Personal Values & $\begin{array}{l}\text { - "My definition of what makes a well rounded human is that a portion or percentage of your time, } \\
\text { - "I } \text { "I have time on my hands and because of my own experiences I thought this is a great thing to do. It's a ministry." } \\
\text { - "Even people who are of limited means. They can do something to help their community." } \\
\text { - "I volunteer everywhere. I have about } 7 \text { or } 8 \text { active volunteer opportunities." } \\
\text { "Anywhere I have lived there is a point where there is a natural outreach into the community and I like to be } \\
\text { - "Involved a certain amount of time." }\end{array}$ \\
\hline Connectedness & $\begin{array}{l}\text { - "I like the fact you can really get to know somebody and understand where they are coming from." } \\
\text { - "You can learn so much from them." } \\
\text { - "It's like a friend you have made in a different area of your life." } \\
\text { - "I am new to the area. I volunteer to meet people." } \\
\text { - "I am fascinated with people." } \\
\text { - "I am rey others company" }\end{array}$ \\
\hline
\end{tabular}


The final theme that emerged was connectedness. It is "the state of being joined or linked or a feeling of belonging to or having affinity with a particular person or group" [28]. This theme initially arose from a preliminary category of socialization. However, after the researchers reviewed the data and refined the themes, they discovered it was more than socialization. Volunteers referred to the riders as their friends and family. It was clear that relationships formed from their interactions and true connections were established. One volunteer participant stated "I like the fact you can really get to know somebody and understand where they are coming from." Volunteer drivers enjoyed the time spent with riders and often spoke of the things they learned from their driving experiences. Many drivers repeatedly signed up for and often rearranged their personal schedules for their favorite riders.

\section{Discussion}

For agencies using volunteers, it is beneficial to understand characteristics and motivations of volunteers to support recruitment and retention efforts. This study aimed to explore the motivations of volunteer drivers for Senior Ride Nashville in order to provide the agency with a volunteer profile and specific strategies to implement into their program. While $63 \%$ of the participants were over 65 years of age, the most consistent finding across both the quantitative and qualitative data was that volunteering is a way to express altruistic concern for others. This was found as the most common motivator in both the VFI and focus group themes. These findings are consistent with previous literature reporting older adults are especially likely to volunteer for altruistic motivations [13] [14] [15] [23]. Maybe because older adults have more time and financial security to pursue opportunities that are not for personal gain.

Like previous research, this study found age to be inversely related to the career function of the VFI [15] [22] [23]. Younger adults are at a time in their lives where they prioritize career and may view volunteerism as a way to explore potential career options, develop one's skills in preparation for a career and network with community members [29]. With predominantly older volunteers, Senior Ride Nashville and other organizations can appeal to younger individuals through the promotion of career specific skill building such expanding knowledge and experience working with seniors. This study found that individuals who reported a medium level of financial security ranked the career function more highly as a motivation to volunteer compared to those who had high or very high levels of financial security. McNamara and Gonzales [20] found similar findings regarding individual resources as a determinant of volunteerism. Individuals just starting their careers may rank their security lower than those who have been in a career for an extended period of time or have retired. Individuals who rank their financial security high may also choose to volunteer for reasons other than career advancement.

In this study, individuals who were widowed, separated, or divorced had the 
highest median scores for the values motivation. Dury et al. [30] found widowhood to be positively related to volunteering while divorce was negatively associated with volunteering. The findings of this study suggest individuals who have experienced relational loss rank altruistic motivations as a core reason they volunteer. This may be because they are looking for ways to care for others because they lost nurturing responsibility in their personal relationships.

The volunteer functions of enhancement, understanding, and protective were all positively related to the likelihood to volunteer in the future. These motivations were examined in the focus group which revealed the volunteers' desire to connect with riders, learn more about their lives, and feel appreciated. Contrary to this study, Stukas et al. [22] found a higher intention to volunteer was related to the VFI values and social functions. The identified functions of enhancement, understanding, and protective are more egoistic than the values function, but still influence the commitment to volunteer. This influence could be because of the increased personal benefit the volunteers feel since they are volunteering to meet their own needs. Throughout the focus group, the theme of connectedness kept reemerging. Connectedness has been identified as an important motivator for volunteer drivers in similar ride programs [7].

Based on the findings, recommendations are made for Senior Ride Nashville and similar organizations to implement. First, in recruiting volunteers, advertisements and marketing emphasizing the relational aspect of the volunteer experience is preferred to solely informational recruitment. When appealing to potential volunteers who are older adults, the emphasis should be on benefits to the riders because they relate most to volunteering for altruistic reasons. When marketing the agency to younger adults, the emphasis should be on the career related skills utilized in the volunteer role. Secondly, to aid in retention of current volunteers, opportunities for socialization are key. The desire to connect with the other riders and volunteers was voiced in the focus groups. This connection could be achieved through community meet-ups, lunch and learns, or volunteer outings. Volunteers also mentioned how much they appreciated the ease of volunteering and organization of the agency. When Senior Ride Nashville staff contacted the volunteers directly, they were more likely to rearrange their schedules to fulfill ride requests. This commitment is only created through relationships with the riders and staff and should be carefully stewarded.

The findings of this research support the continuous efforts of understanding volunteerism in order to better serve older adults in the Nashville community. However, it is prudent to caution against over generalization of these suggestions due to limitations in the research. One limitation of this study is the small sample size of the study. $(\mathrm{N}=33)$ representing a response rate of $45 \%$, thus making the findings ungeneralizable. Additionally, only information on those individuals who participated in the survey is available for analysis and cannot be compared to those volunteer drivers who chose not to participate. This may present a bias in the available data and may be a direction for further study. Subjects were from one small volunteer transportation agency in the Southeast 
United States and there was limited diversity amongst the participants. While some significant information was generated for Senior Ride Nashville, it may not be applicable to other volunteer agencies. Lastly, due to technical error, a portion of audio recording from one of the focus groups was unable to be transcribed verbatim. The thematic analysis of that focus group mainly relied on the handwritten notes by the researchers. Future research may explore the impact of the above recommendations for recruitment and retention.

This study has implications for the field of occupational therapy. Occupational therapy practitioners support communities experiencing occupational injustices by advocating for programs and services [4] [5] [6]. Volunteer ride programs promote access to transportation and community participation for older adults, enhancing their occupational engagement. Volunteering is also an occupation and can be used to increase participation and quality of life in all adults. Occupational therapists need to be knowledgeable about available resources in the community that can meet the transportation needs of older adults, as well as consult with local agencies to implement volunteer ride programs in the future.

\section{Summary}

In summary, this research sought to examine the motivations of volunteer drivers for a nonprofit organization that provides rides to seniors who can no longer drive. As the population of older adults with limited mobility increases with the aging of America, these services are becoming more urgent in allowing seniors to age in place. The findings support the existing research indicating that "values" (a way to express altruistic and humanitarian values) is a significant motivator for volunteer drivers in Senior Ride Nashville. Additionally, the participants of this study reported high levels of well-being, financial security and intention to continue volunteering. This is similar to the findings in the existing research that also indicated "values" as a significant motivator. Volunteering allows individuals to contribute to the well-being of others in their community and to meet their own psychosocial needs. Therefore, when considering strategies for recruitment and retention, keeping a focus on the relational aspect of the volunteer experience, between both riders and volunteers, volunteers and staff, and between volunteers is suggested.

\section{Acknowledgements}

This research was partially supported by Mary Dietrich, Ph.D., Professor of Statistics and Measurement in the School of Nursing, Vanderbilt University, Nashville, Tennessee. Her knowledge of statistical analysis provided crucial information that contributed to the interpretation of the results.

\section{Conflicts of Interest}

The authors declare no conflicts of interest regarding the publication of this paper. 


\section{References}

[1] American Occupational Therapy Association (2014) Occupational Therapy Practice Framework: Domain and Process (3rd ed.). American Journal of Occupational Therapy, 68, S1-S48. https://doi.org/10.5014/ajot.2014.682006

[2] Tennessee Commission on Aging and Disability (2018) The State of Aging in Tennessee: A County-by-County Snapshot.

https://www.tn.gov/content/dam/tn/aging/documents/2018\%20State\%20of\%20Agi ng\%20in\%20Tennessee.pdf

[3] United States Census Bureau (2017) Population 65 Year and over in the United States.

https://factfinder.census.gov/faces/tableservices/jsf/pages/productview.xhtml?pid=A CS 15 1YR S0201\&prodType $=$ table

[4] American Occupational Therapy Association (2005) Occupational Therapy Code of Ethics. American Journal of Occupational Therapy, 59, 639-642.

https://doi.org/10.5014/ajot.59.6.639

[5] AOTA's Societal Statement on Livable Communities (2009) AOTA's Societal Statement on Livable Communities. American Journal of Occupational Therapy, 63, 847-848. https://doi.org/10.5014/ajot.63.6.847

[6] United Nations (2007) Rights and Dignity of Persons with Disabilities, Article 19. https://www.un.org/development/desa/disabilities/convention-on-the-rights-of-per sons-with-disabilities/article-19-living-independently-and-being-included-in-the-co mmunity.html

[7] Kerschner, H. and Rousseau, M.H. (2008) Volunteer Drivers: Their Contributions to Older Adults and to Themselves. Gerontology and Geriatrics Education, 29, 383-397. https://doi.org/10.1080/02701960802497969

[8] DeGood, K. (2015) Aging in Place Stuck without Options: Fixing the Mobility Crisis Threatening the Baby Boom Generation.

http://t4america.org/docs/SeniorsMobilityCrisis.pdf

[9] Corporation for National and Community Service (n.d.) City Rankings by Volunteer Rate. https://www.nationalservice.gov/vcla/city-rankings-volunteer-rate

[10] Clary, E., Ridge, R., Stukas, A., Snyder, M., Copeland, J., Haugen, J. and Miene, P. (1998) Personality Processes and Individual Differences. Understanding and Assessing the Motivations of Volunteers: A Functional Approach. Journal of Personality and Social Psychology, 74, 1516-1530. https://doi.org/10.1037//0022-3514.74.6.1516

[11] Penner, L.A. (2002) Dispositional and Organizational Influences on Sustained Volunteerism: An Interactionist Perspective. Journal of Social Issues, 58, 447-467. https://doi.org/10.1111/1540-4560.00270

[12] Clary, E.G. and Snyder, M. (1999) The Motivations to Volunteer: Theoretical and Practical Considerations. Current Directions in Psychological Science, 8, 156-159. https://doi.org/10.1111/1467-8721.00037

[13] Hustinx, L., Cnaan, R.A. and Handy, F. (2010) Navigating Theories of Volunteering: A Hybrid Map for a Complex Phenomenon. Journal for the Theory of Social Behaviour, 40, 410-434. https://doi.org/10.1111/j.1468-5914.2010.00439.x

[14] Thoits, P.A. and Hewitt, L.N. (2001) Volunteer Work on Well-Being. Journal of Health and Social Behavior, 42, 115-131. https://doi.org/10.2307/3090173

[15] Morrow-Howell, N., Lee, Y.S., McCrary, S. and McBride, A. (2014) Volunteering as a Pathway to Productive and Social Engagement among Older Adults. Health Beha- 
vior and Health Education, 41, 84S-90S. https://doi.org/10.1177/1090198114540463

[16] Finkelstein, M.A. (2009) Intrinsic vs. Extrinsic Motivational Orientations and the Volunteer Process. Personality and Individual Differences, 46, 653-658. https://doi.org/10.1016/j.paid.2009.01.010

[17] Widjaja, E. (2010) Motivation behind Volunteerism. CMC Senior Theses, 1-36. https://scholarship.claremont.edu/cmc theses/4/

[18] Pardasani, M. (2018) Motivation to Volunteer among Senior Center Participants. Journal of Gerontological Social Work, 61, 313-333. https://doi.org/10.1080/01634372.2018.1433259

[19] Agostinho, D. and Paco, A. (2012) Analysis of the Motivations, Generativity and Demographics of the Food Bank Volunteer. International Journal of Nonprofit and Voluntary Sector Marketing, 17, 249-262. https://doi.org/10.1002/nvsm.1469

[20] McNamara, T.K. and Gonzales, E. (2011) Volunteer Transitions among Older Adults: The Role of Human, Social, and Cultural Capital in Later Life. Journals of Gerontology_Series B Psychological Sciences and Social Sciences, 66, 490-501. https://doi.org/10.1093/geronb/gbr055

[21] Principi, A., Schippers, J., Naegele, G., Di Rosa, M. and Lamura, G. (2016) Understanding the Link between Older Volunteers' Resources and Motivation to Volunteer. Educational Gerontology, 42, 144-158. https://doi.org/10.1080/03601277.2015.1083391

[22] Stukas, A., Hoye, R., Nicholson, M., Brown, K. and Aisbett, L. (2016) Motivations to Volunteer and Their Associations with Volunteers' Well-Being. Nonprofit and Voluntary Sector Quarterly, 45, 112-132. https://doi.org/10.1177/0899764014561122

[23] Allison, L.D., Okun, M.A. and Dutridge, K.S. (2002) Assessing Volunteer Motives: A Comparison of an Open-Ended Probe and Likert Rating Scales. Journal of Community and Applied Social Psychology, 12, 243-255. https://doi.org/10.1002/casp.677

[24] Corcoran, M.A. (2017) Using Mixed-Methods Designs to Study Therapy and Its Outcomes. In: Taylor, R.R., Ed., Kielhofner's Research in Occupational Therapy: Methods of Inquiry for Enhancing Practice, F. A. Davis Company, Philadelphia, 488-497.

[25] Creswell, J.W. (2009) Research Design: Qualitative, Quantitative, and Mixed Methods Approaches. 3rd Edition, Sage Publications, Inc., Thousand Oaks.

[26] Braun, V. and Clarke, V. (2006) Using Thematic Analysis in Psychology. Qualitative Research in Psychology, 3, 77-101. https://doi.org/10.1191/1478088706qp063oa

[27] Dictionary.com (n.d.) Altruism. https://www.dictionary.com/browse/altruism

[28] Cambridge Business English Dictionary (2019) Connectedness. https://dictionary.cambridge.org/us/dictionary/english/connectedness

[29] Souza, K.A. and Dhami, M.K. (2008) A Study of Volunteers in Community-Based Restorative Justice Programs. Canadian Journal of Criminology and Criminal Justice, 50, 31-57. https://doi.org/10.3138/cjccj.50.1.31

[30] Dury, S., De Donder, L., De Witte, N., Buffel, T., Jacquet, W. and Verté, D. (2015) To Volunteer or Not: The Influence of Individual Characteristics, Resources, and Social Factors on the Likelihood of Volunteering by Older Adults. Nonprofit and Voluntary Sector Quarterly, 44, 1107-1128. https://doi.org/10.1177/0899764014556773 


\section{Appendix}

\section{Appendix A. Volunteer Demographic Information Form}

\section{Section 1: General Information}

1) What is your age in years?

2) What is your gender?

Female Male Other Prefer not to answer

3) What is your ethnic background?

Caucasian African American Hispanic Other

4) What is your marital status?

Single Married Divorced/Separated Widowed

5) What is your living arrangement?

$$
\text { Alone }
$$

With family without children With family and children

With non-family members

6) What is the highest level of education you obtain?

Less than high school High school graduate Some college College graduate Post-professional graduate

7) What is your employment status? Full-time Part-time Not-employed Student

\section{Retired}

8) How would you rate your financial security?

$$
\text { Very Low__ Low___ Medium }
$$
High Very High

9) How important is religion/spirituality to you? Not at all A little Neutral Somewhat Very

10) How do you perceive your general health? Very Poor Poor Average Good Very Good

\section{Section 2: Volunteering Information}

11) How did you hear about Senior Ride Nashville? Friend/ Family Member Internet Search Community Center Other (please list):

12) How long have you been volunteering at Senior Ride Nashville? 0 - 3 months 4 - 6 months 7 - 9 months $10-12$ months More than 12 months

13) How frequently have you volunteered for other organizations in the past 5 years?

Not at all Not Often Somewhat Often Very Often

14) Do you currently volunteer for another organization other than Senior Ride Nashville?

No__ Yes

15) Since you began volunteering with Senior Ride Nashville, how has your 
frequency of providing rides changed? Decreased frequency Remained the same Increased frequency

16) How likely are you to volunteer for Senior Ride Nashville in the next 12 months?

Likely Not likely Less likely Somewhat Likely Very

\section{Appendix B. Focus Group Questions}

1) Describe your favorite or best ride.

a) Describe your relationships with the riders.

b) What drew you to volunteer for SRN?

2) Share your reasons for continuing to volunteer with Senior Ride Nashville.

a) Describe SRN's staff support in your continuing to provide rides.

b) What will contribute to your continued volunteering in the future?

3) We have various ways to communicate needs for ride pick-ups, what usually prompts you to sign up to give a ride?

a) Do you rely on the cues (i.e. emails, phone calls, notifications)?

b) Does a routine help (logging on to the software every Thursday)?

4) Describe what influences your decision to give a particular ride, given the information provided to you on Assisted Rides? (Rider, total estimated time, type of ride, total estimated mileage, part of town, other.)

5) Describe the parts of the volunteer orientation that made you feel successful as a volunteer driver.

Now that you have had the experience of a volunteer driver, describe any additional training that would have been helpful to you.

6) Describe any unexpected experiences you have faced in your volunteer role for which you didn't feel prepared.

a) Tell us more about how you handled that situation.

b) Given this experience, describe anything SRN could have done during the orientation or during the situation to support you in your role?

7) If you have had other service/volunteer experiences, what were things you liked about your experience and would want to see SRN implement in the future?

\section{Abbreviation}

SRN: Senior Ride Nashville. 